\title{
Loredana Bolzan, Segreti e bugie. Balzac nel cuore femminile
}

\section{Marco Stupazzoni}

\section{Q OpenEdition}

1 Journals

\section{Edizione digitale}

URL: http://journals.openedition.org/studifrancesi/27757

DOI: 10.4000/studifrancesi.27757

ISSN: 2421-5856

\section{Editore}

Rosenberg \& Sellier

\section{Edizione cartacea}

Data di pubblicazione: 31 décembre 2006

Paginazione: 620-621

ISSN: 0039-2944

\section{Notizia bibliografica digitale}

Marco Stupazzoni, «Loredana Bolzan, Segreti e bugie. Balzac nel cuore femminile », Studi Francesi

[Online], 150 (L | III) | 2006, online dal 30 novembre 2015, consultato il 08 novembre 2020. URL : http:// journals.openedition.org/studifrancesi/27757 ; DOI : https://doi.org/10.4000/studifrancesi.27757

Questo documento è stato generato automaticamente il 8 novembre 2020.

\section{(c) (i) (9)}

Studi Francesi è distribuita con Licenza Creative Commons Attribuzione - Non commerciale - Non opere derivate 4.0 Internazionale. 


\title{
Loredana Bolzan, Segreti e bugie. Balzac nel cuore femminile
}

\author{
Marco Stupazzoni
}

\section{NOTIZIA}

LOREDANA BOLZAN, Segreti e bugie. Balzac nel cuore femminile, «Rivista di Letterature moderne e comparate», vol. LVIII, nuova serie, Fasc. 1, gennaio-marzo 2005, pp. 33-57.

1 L'idea di una raccolta omogenea di studî sull'universo femminile intitolata: Études de femme nasce e si matura progressivamente in Balzac a partire grosso modo dal 1832 come testimoniano le numerose tracce di questo progetto presenti nella Correspondance. Oggetto di studio privilegiato dallo sterminato campionario di tipologie umane e sociali quali sono descritte da Balzac nella sua opera, la natura femminile ha come sua primaria connotazione quella di resistere ad ogni razionale delucidazione e ad ogni univoca rappresentazione di tipo realistico: per questo, la sua trasposizione letteraria attraverso le forme della scrittura narrativa può considerarsi, sia dal punto di vista narratologico sia da quello più propriamente metodologico, una sfida di ordine ontologico poiché il suo oggetto, il cuore femminile, «sembra per definizione refrattario non solo a ogni conoscenza unilaterale ma all'enunciazione stessa della propria verità» (p. 33). La trasfigurazione romanzesca di questa insondabile dimensione del cuore umano propria dell'universo femminile, vista nelle sue implicazioni tematiche e metodologiche, implica anche il ricorso a tecniche e a strategie di scrittura predisposte e funzionali alla esplicitazione di tutte quelle sofisticate varianti connesse alla duplice categoria 'menzogna-verità': accanto al classico ricorso alle tecniche della dissimulazione inerenti alle strategie di seduzione, Balzac ci propone, all'interno della variegata schiera dei suoi 'racconti al femminile', anche l'intermittente complicità tra opacità e mistero del vero e discorso che trova il suo punto estremo di confusione semiologia e morale nella depravazione incarnata in modo sublime dalla princesse de Cadignan. Nell'affermare infatti «il primato della mistificazione come regola dei rapporti interpersonali» (p. 50), il racconto: Les Secrets de la princesse de Cadignan 
amplifica le vertigini di un paradosso sentimentale, mondano e morale, che «dà luogo alla doppia verità intorno alla principessa, in quanto la cruda legge dell'opinione, che ne ha certificato irreversibilmente l'identità, mette a nudo il conflitto fra l'apparire e l'essere, con il prevalere del marchio indelebile della depravazione di cui gli altri propagano la fama» (p. 51). 